\title{
Implementation of a medical oncology fellow-initiated financial toxicity screening program in outpatient medical oncology clinics
}

\author{
Hala T. Borno ${ }^{1}$ (D) ${ }^{\text {a }}$, Nichole Legaspi ${ }^{1}$, Sam Brondfield $^{1}$, Errol Philip ${ }^{2}$, Pelin Cinar ${ }^{1}$ Li Zhang $^{3}$ \\ 1 Department of Medicine, Division of Hematology/Oncology, University of California San Francisco, San Francisco, CA, USA, 2 School of Medicine, \\ University of California San Francisco, San Francisco, CA, USA, ${ }^{3}$ Department of Medicine, Division of Hematology/Oncology, University of California \\ San Francisco, San Francisco, CA, USA; Department of Epidemiology and Biostatistics, University of California San Francisco, San Francisco, CA, USA \\ Keywords: medical oncology, quality improvement, financial toxicity, cancer disparities
}

https://doi.org/10.53876/001c.27349

\section{International Journal of Cancer Care and Delivery}

\section{Introduction}

The National Cancer Institute defines financial toxicity as "problems a patient has related to costs of cancer care." Financial toxicity is a critical problem in cancer treatment and one that remains conventionally outside of clinical discussion and treatment decision-making.

\section{Methods}

This is a feasibility pilot study of the implementation of a medical oncology fellow-led financial toxicity screening intervention program at the Helen Diller Family Comprehensive Cancer Center (HDFCCC) at the University of California San Francisco. Fellows were asked to conduct and document financial toxicity screening of patients seen in medical oncology outpatient clinics from August 2017 to March 2018 in the electronic medical record.

\section{Results}

At baseline, no fellows documented financial toxicity screening. Screening rates peaked at $49 \%$, however at the end of the intervention the screening rate decreased to $11 \%$ among participants.

\section{Discussion}

The results of the pilot feasibility study revealed that a fellow-led financial toxicity screening program in medical oncology clinics rendered low adherence to patient screening. Future research will need to develop mechanisms for identifying patients who may experience high levels of financial distress in medical oncology practice.

\section{BACKGROUND}

The National Cancer Institute defines financial toxicity as "problems a patient has related to costs of cancer care." " $\mathrm{Fi}$ nancial Toxicity” 2019) Financial toxicity is a critical problem in cancer treatment and remains conventionally outside of clinical discussion and treatment decision-making. Prior studies have shown that a cancer diagnosis can be associated with long-term financial implications, including an increased risk of debt and bankruptcy.(Banegas et al. 2016) Moreover, financial toxicity leads to behavior changes in patient adherence to treatment that can impact cancer outcomes and quality of life.(Bestvina et al. 2014; Zafar et al. 2013; Nipp et al. 2016) To date, no standardized screening approach for assessing clinical financial toxicity exists in the United States, and the medical oncologist's role in detecting financial toxicity among patients with cancer remains poorly defined.

\section{METHODS}

In this feasibility pilot study, we implemented a fellow-led financial toxicity screening intervention program at the Helen Diller Family Comprehensive Cancer Center (HDFCCC)

\footnotetext{
Corresponding author:

Hala T. Borno

Hala.borno@ucsf.edu

550 16th Street, 6th Floor, Box 3211, Office 6554

San Francisco, CA 94158

tel: (415) 476-4616 | fax: (415) 353-7107
} 


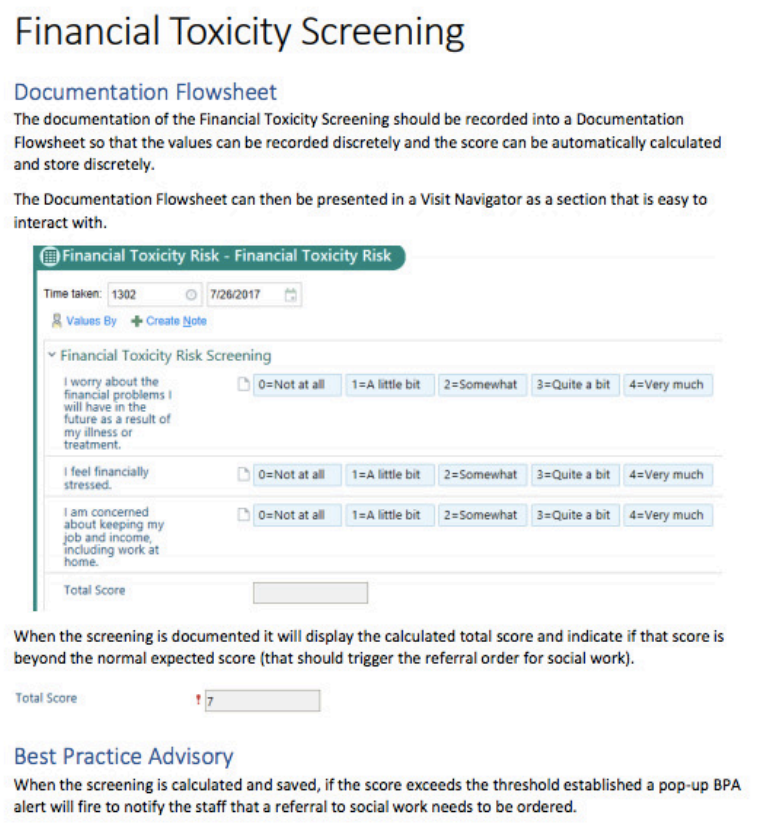

Figure 1.

at the University of California San Francisco to standardize the documentation of financial toxicity screening in the electronic medical record for patients seen in medical oncology outpatient clinics from August 2017 to March 2018.

Medical oncology fellows performed the study intervention of screening new or established patients seen in outpatient medical oncology clinics using a structured three-item financial toxicity screen adapted from the 11-item COST patient-reported outcome measure.(de Souza et al. 2014) The intervention details are presented as a checklist in the Appendix using the TiDIER Format. As seen in Figure 1, electronic medical record documentation of financial toxicity screening values was recorded in a documentation flowsheet, and the total score was automatically calculated and stored discretely. The three screening questions were: (1) I worry about the financial problems I will have in the future as a result of my illness or treatment; (2) I feel financially stressed; (3) I am concerned about keeping my job and income, including work at home. Patients responded to each question using a Likert-like scale: $0=$ Not at all; $1=\mathrm{A}$ little bit; $2=$ Somewhat; $3=$ Quite a bit; and 4=Very much. A total score of 6 or greater was defined as high financial distress. It triggered a best practice advisory pop-up alert to notify the medical oncology fellow that a social work referral needs to be ordered. The three questions and score threshold were identified by a team of oncology social workers from the 11-item COST PROM to reflect actionable patient concerns in the medical oncology clinic. The goal for the intervention program was to achieve a minimal screening rate of $30 \%$ among patients seen in the medical oncology clinic. Electronic records for all patients seen by each participating fellow during two randomly selected clinic half-days per fellow per month were randomly audited, and screening frequency for each fellow was recorded. Institutional review board approval was received for this study.

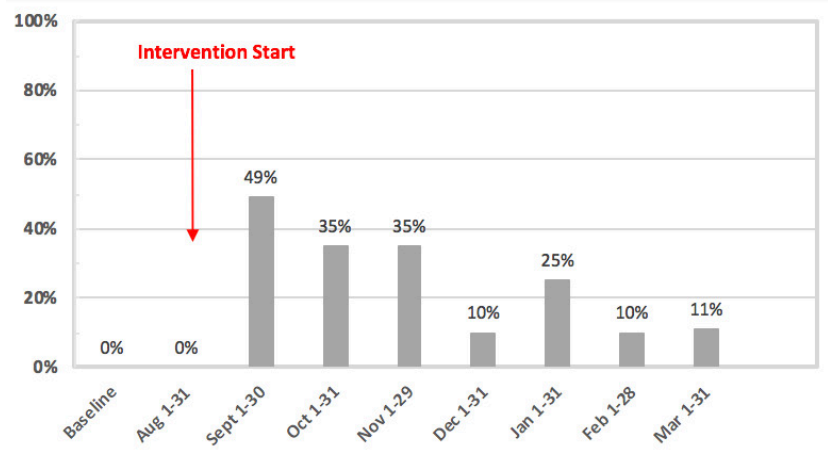

Figure 2. Percent of patients screened for Financial Toxicity

Demographic and clinical characteristics were summarized by descriptive statistics. In general, frequency distribution and percentage were used to summarize categorical variables, and median with range (min, max) was used to describe continuous variables. Comparison of the continuous variables between two groups was assessed using the Wilcoxon sum rank test. Pearson's Chi-squared test was applied to test if there is a statistical association between two categorical variables. The statistical significance was declared at $P<0.05$, and all the statistical analyses were done by the statistical computing software R.

\section{RESULTS}

During the program, eleven medical oncology fellows participated and rotated in eight disease-specific medical oncology clinics (gastrointestinal, thoracic, sarcoma, genitourinary, breast and cutaneous, head and neck, gynecologic). Fellows worked with twenty-six medical oncology attending physicians. As seen in Figure 2, at the baseline of the study, no fellows documented financial toxicity measures among patients seen in the clinic. During the study period, the screening rates varied every two weeks and peaked at $49 \%$. At the end of the intervention, the screening rate decreased to $11 \%$. During the intervention period, the majority of screenings $(51.7 \%)$ were completed by two participating fellows (supplement).

A total of 120 patients were screened during the study period. The patient characteristics in this intervention are summarized in Table 1. The majority of screened patients were female (53\%) and white (71\%). Fewer patients were Black (1.7\%), Asian (10\%), or other (17\%). Among screened patients, $21 \%$ were single, $64 \%$ were married, and $8 \%$ were divorced, while $35 \%$ had no dependents, $35 \%$ had 1 dependent, $17 \%$ had 2 dependents, and $13 \%$ had >= 3 dependents. Further, 39\% had stable insurance, which was defined as having no insurance change. The majority of participants (69\%) had non-metastatic disease; however, only $12 \%$ were treated with curative intent. The majority of participants (48\%) were diagnosed $>18$ months prior to the screening date. Forty-three percent were on their third line or higher course of therapy. The majority of participants (84\%) were receiving the standard of care treatment. Among the 41 
(15\%) clinical trial participants, the majority (47\%) were enrolled in a phase II study.

Among screened patients, the highest median financial distress scores were observed in gynecologic oncology [11, $0-12]$, breast oncology [5, 0-12], and gastrointestinal oncology [3, 0-12] (supplement). A significantly greater percentage of screened female patients had a positive screen compared to their male counterparts $(75 \%$ vs. $24 \%, \mathrm{p}=0.002)$. Further, patients who had an insurance change during cancer treatment had a higher percentage of positive distress screens than patients with stable insurance $(p=0.043)$. No significant differences were observed in positive screening rates by race/ethnicity, marital status, number of dependents, disease group, stage of diagnosis, or line of therapy.

\section{DISCUSSION}

The current study observed low fellow-initiated financial toxicity screening rates overall. Whereas the target screening rate of $30 \%$ was achieved at the mid-point of the intervention period, this was not sustained. Future interventions will need to improve provider adherence to screening during the clinical visit. Another important exploratory observation of this study is that female patients and patients with changes in insurance coverage had significantly higher rates of financial distress; however, these observations will need to be validated in a larger study.

There are limitations to the current study that are worth noting. This was a single-site fellow-led initiative at an academic medical center. Therefore the participating clinicians were a small sample, and the study's conclusions are not necessarily generalizable to patients cared for in community oncology practices. Moreover, to date, no clinical financial toxicity screening tool exists for oncologists to use in clinical practice. Therefore, we adapted the 11-item COST PROM(de Souza et al. 2014) to develop a 3-item questionnaire through discussion with social work on what questions best reflected common patient concerns. Thus, the 3 -item questionnaire used in this study will need to be validated in a larger study. Lastly, this study implemented a financial toxicity screening program among medical oncology trainees. The underlying rationale for this design was that oncology fellows rotate through different oncology clinics and see patients with a variety of cancers. However, these fellows may lack the longitudinal relationships with patients that may enhance the feasibility of financial toxicity screening. Future research will need to incorporate a clinician-led screening intervention in oncology clinics where the providers who perform financial toxicity screening are seeing the same patients longitudinally.

Despite these limitations, this study has several strengths. To the best of our knowledge, this is the first study assessing the feasibility of clinician-initiated financial toxicity screening in medical oncology clinics. To date, no operationalized method for identifying patients at risk for high levels of financial distress during cancer treatment exist. Importantly, we believe the current study adds to the growing literature examining mechanisms for identifying patients at risk for financial toxicity while receiving cancer treatment.

\section{CONCLUSIONS}

The results of the current pilot feasibility study revealed that a fellow-led financial toxicity screening program in medical oncology clinics has poor adherence. This study suggests that alternative screening strategies must be developed to ensure that financial toxicity is addressed in the clinical visit. Future research will need to examine alternative mechanisms for identifying patients who may experience high levels of financial distress during their disease trajectory.

\section{ABBREVIATIONS}

HDFCCC: Helen Diller Family Comprehensive Cancer Center

PROM: Patient-Reported Outcome Measures

\section{ETHICS OF APPROVAL AND CONSENT FOR PARTICIPATION}

Institutional review board at the University of California San Francisco as well as Protocol Review and Monitoring Committee approval was obtained for this study.

\section{CONSENT FOR PUBLICATION}

Non-applicable

\section{AVAILABILITY OF DATA AND MATERIALS}

Borno, Legaspi, Brondfield, Phillip acquired data for this study. All data generated or analysed during this study are available from corresponding author on reasonable request.

\section{COMPETING INTERESTS/DISCLOSURES}

All authors have no disclosures or conflicts of interest.

\section{FUNDING}

No funding was obtained for this research study.

\section{AUTHOR CONTRIBUTIONS}

Study concept and design: Borno, Legaspi, Brondfield, Philip, Cinar

Analysis and interpretation of data: Borno, Legaspie, Brondfield, Philip, Cinar, Zhang

Drafting of the manuscript: Borno, Legaspi, Brondfield, Philip, Cinar, Zhang

Critical revision of manuscript: Borno, Legaspi, Brondfield, Philip, Cinar, Zhang

Statistical analysis: Zhang

Obtained funding: None.

Other: Borno is supported by the Prostate Cancer Foundation. 


\begin{tabular}{|c|c|c|c|c|c|}
\hline & & & $\begin{array}{l}\text { Financial } \\
\text { Distress }\end{array}$ & & \\
\hline & & Total $(\mathrm{N}=120)$ & $\begin{array}{l}\text { Negative Screen } \\
(\mathrm{N}=83)\end{array}$ & $\begin{array}{l}\text { Positive Screen } \\
(\mathrm{N}=37)\end{array}$ & $\begin{array}{l}\mathrm{P} \text { - } \\
\text { value }\end{array}$ \\
\hline Age (median[range]) & $\begin{array}{l}63.00[27.00, \\
90.00]\end{array}$ & $\begin{array}{l}67.00[30.00, \\
81.00]\end{array}$ & $\begin{array}{l}61.00[27.00, \\
90.00]\end{array}$ & 0.011 & \\
\hline \multicolumn{6}{|l|}{ Sex } \\
\hline & Male & $55(46.7)$ & $46(83.6)$ & $9(24.3)$ & 0.002 \\
\hline & Female & $64(53.3)$ & $36(56.2)$ & $28(75.7)$ & \\
\hline \multirow[t]{6}{*}{ Race } & & & & & 0.182 \\
\hline & White & $85(70.8)$ & $64(77.1)$ & $21(56.8)$ & \\
\hline & Black & $2(1.7)$ & $1(1.2)$ & $1(2.7)$ & \\
\hline & Asian & $12(10.0)$ & $6(7.2)$ & $6(16.2)$ & \\
\hline & Other & $20(16.7)$ & $11(13.3)$ & $9(24.3)$ & \\
\hline & Unknown & $1(0.8)$ & $1(1.2)$ & $0(0.0)$ & \\
\hline \multirow[t]{6}{*}{ Marital Status } & & & & & 0.079 \\
\hline & Single & $25(20.8)$ & $12(14.5)$ & $13(35.1)$ & \\
\hline & Married & $77(64.2)$ & $58(69.9)$ & $19(51.4)$ & \\
\hline & Divorced & $10(8.3)$ & $6(7.2)$ & $4(10.8)$ & \\
\hline & Widowed & $7(5.8)$ & $6(7.2)$ & $1(2.7)$ & \\
\hline & Unknown & $1(0.8)$ & $1(1.2)$ & $0(0.0)$ & \\
\hline \multirow[t]{5}{*}{$\begin{array}{l}\text { Number of } \\
\text { Dependents }\end{array}$} & & & & & 0.499 \\
\hline & 0 & $32(35.2)$ & $20(31.7)$ & $12(42.9)$ & \\
\hline & 1 & $32(35.2)$ & $25(39.7)$ & $7(25.0)$ & \\
\hline & 2 & $15(16.5)$ & $9(14.3)$ & $6(21.4)$ & \\
\hline & $>=3$ & $12(13.0)$ & $9(14.0)$ & $3(10.7)$ & \\
\hline \multirow[t]{3}{*}{ Stable Insurance } & & & & & 0.043 \\
\hline & Yes & $60(39.2)$ & $38(45.8)$ & $9(24.3)$ & \\
\hline & No & $73(60.8)$ & $45(54.2)$ & $28(75.7)$ & \\
\hline \multirow[t]{3}{*}{ Limited Insurance } & & & & & 0.467 \\
\hline & Yes & $3(2.5)$ & $1(1.2)$ & $2(5.4)$ & \\
\hline & No & $130(97.5)$ & $81(98.8)$ & $35(94.6)$ & \\
\hline \multirow[t]{9}{*}{ Disease Group } & & & & & 0.085 \\
\hline & Breast & $25(20.8)$ & $13(15.7)$ & $12(32.4)$ & \\
\hline & Cutaneous & $14(11.7)$ & $11(13.3)$ & $3(8.1)$ & \\
\hline & Gastrointestinal & $15(12.5)$ & $9(10.8)$ & $6(16.2)$ & \\
\hline & Genitourinary & $37(30.8)$ & $31(37.3)$ & $6(16.2)$ & \\
\hline & Head and Neck & $3(2.5)$ & $2(2.4)$ & $1(2.7)$ & \\
\hline & Thoracic & $21(17.5)$ & 15 (18.1) & $6(16.2)$ & \\
\hline & Sarcoma & $1(0.8)$ & $1(1.2)$ & $0(0.0)$ & \\
\hline & Gynecologic & $4(3.3)$ & $1(1.2)$ & $3(8.1)$ & \\
\hline \multirow[t]{3}{*}{ Cancer Stage } & & & & & 0.656 \\
\hline & Non-metastatic & $37(69.2)$ & $18(21.7)$ & $6(16.2)$ & \\
\hline & Metastatic & $96(80.0)$ & $65(78.3)$ & $31(83.8)$ & \\
\hline \multirow[t]{4}{*}{$\begin{array}{l}\text { Time Since Diagnosis } \\
\text { (months) }\end{array}$} & & 0.203 & & & \\
\hline & $<=6$ & $36(30.0)$ & $22(26.5)$ & $14(37.8)$ & \\
\hline & $>6-<=12$ & $18(15.0)$ & $16(19.3)$ & $2(5.4)$ & \\
\hline & $>12-<=18$ & $8(6.7)$ & $6(7.2)$ & $2(5.4)$ & \\
\hline
\end{tabular}




\begin{tabular}{|c|c|c|c|c|c|}
\hline & $>18$ & $58(48.3)$ & $39(47.0)$ & $19(51.4)$ & \\
\hline \multirow[t]{4}{*}{ Goal of Therapy } & & & & & 0.534 \\
\hline & Curative & $13(11.9)$ & $9(12.2)$ & $4(11.4)$ & \\
\hline & Non-Curative & $46(42.2)$ & $32(43.2)$ & $14(40.0)$ & \\
\hline & Unknown & $49(45.0)$ & $33(44.6)$ & $16(45.7)$ & \\
\hline \multirow[t]{4}{*}{ Line of Therapy } & & & & & 0.829 \\
\hline & $1 \mathrm{st}$ & $36(32.7)$ & $24(32.0)$ & $12(34.3)$ & \\
\hline & 2nd & $26(23.6)$ & $19(25.3)$ & $7(20.0)$ & \\
\hline & $>=3 r d$ & $48(43.6)$ & $32(42.7)$ & $16(45.7)$ & \\
\hline \multicolumn{6}{|l|}{ Treatment Plan } \\
\hline & Standard of care & $92(84.4)$ & $62(83.8)$ & $30(85.7)$ & 1 \\
\hline & $\begin{array}{l}\text { Therapeutic } \\
\text { Clinical Trial }\end{array}$ & $41(15.6)$ & $21(16.2)$ & $7(14.3)$ & \\
\hline \multirow[t]{4}{*}{ Phase of Clinical Trial } & & & & & 0.153 \\
\hline & I & $5(29.4)$ & $5(41.7)$ & $0(0.0)$ & \\
\hline & II & $8(47.1)$ & $4(33.3)$ & $4(80.0)$ & \\
\hline & III & $4(23.5)$ & $3(25.0)$ & $1(20.0)$ & \\
\hline \multirow[t]{3}{*}{ Primary Language } & & & & & 0.16 \\
\hline & English & $111(83.4)$ & $78(94.0)$ & $33(89.2)$ & \\
\hline & Non-English & $22(16.5)$ & $5(6.0)$ & $4(10.8)$ & \\
\hline
\end{tabular}

\section{ACKNOWLEDGMENT}

Submitted: July 21, 2021 PDT, Accepted: August 09, 2021 PDT

Borno is supported by the Prostate Cancer Foundation and Lazarex Cancer Foundation. 


\section{REFERENCES}

Banegas, Matthew P., Gery P. Guy Jr., Janet S. de Moor, Donatus U. Ekwueme, Katherine S. Virgo, Erin E. Kent, Stephanie Nutt, Zhiyuan Zheng, Ruth Rechis, and K. Robin Yabroff. 2016. "For Working-Age Cancer Survivors, Medical Debt And Bankruptcy Create Financial Hardships." Health Affairs (Project Hope) 35 (1): 54-61. https://doi.org/10.1377/hlthaff.2015.0830. Bestvina, C. M., L. L. Zullig, C. Rushing, F. Chino, G. P. Samsa, I. Altomare, J. Tulsky, et al. 2014. "PatientOncologist Cost Communication, Financial Distress, and Medication Adherence." J Oncol Pract 10 (3): 162-67. https://doi.org/10.1200/JOP.2014.001406.

“Financial Toxicity.” 2019. NCI Dictionary of Cancer Terms. https://www.cancer.gov/publications/dictionar ies/cancer-terms/def/financial-toxicity.
Nipp, R. D., H. Lee, E. Powell, N. E. Birrer, E. Poles, D. Finkelstein, K. Winkfield, S. Percac-Lima, B. Chabner, and B. Moy. 2016. "Financial Burden of Cancer Clinical Trial Participation and the Impact of a Cancer Care Equity Program.” Oncologist 21 (4): 467-74. http s://doi.org/10.1634/theoncologist.2015-0481.

Souza, J. A. de, B. J. Yap, F. J. Hlubocky, K. Wroblewski, M. J. Ratain, D. Cella, and C. K. Daugherty. 2014. “The Development of a Financial Toxicity Patient-Reported Outcome in Cancer: The COST Measure." Cancer 120 (20): 3245-53. https://doi.org/10.1002/cncr.28814.

Zafar, S. Y., J. M. Peppercorn, D. Schrag, D. H. Taylor, A. M. Goetzinger, X. Zhong, and A. P. Abernethy. 2013. "The Financial Toxicity of Cancer Treatment: A Pilot Study Assessing out-of-Pocket Expenses and the Insured Cancer Patient's Experience." Oncologist 18 (4): 381-90. https://doi.org/10.1634/theoncologist.20 12-0279. 


\section{Intervention Description Checklist using TiDIER Format}

\begin{tabular}{|c|c|}
\hline \multicolumn{2}{|c|}{ THE INTERVENTION SCREENING TOOL } \\
\hline 1 & $\begin{array}{l}\text { Clinician initiated 3-item financial toxicity screening instrument adapted from the 11-item COST patient-reported outcome } \\
\text { measure. }\end{array}$ \\
\hline \multicolumn{2}{|c|}{ PURPOSE OF INTERVENTION } \\
\hline 2 & $\begin{array}{l}\text { Implement an in-clinic financial toxicity screening tool for cancer patients in order to identify patients at high financial } \\
\text { toxicity risk during cancer treatment. }\end{array}$ \\
\hline \multicolumn{2}{|c|}{ INTERVENTION COMPONENTS } \\
\hline 3 & $\begin{array}{l}\text { In medical oncology clinics, clinicians utilized the 3-item financial toxicity screening tool to identify patients at high risk of } \\
\text { financial toxicity. The screening tool rendered a score between } 1 \text { and } 12 \text { for each patient. }\end{array}$ \\
\hline 4 & $\begin{array}{l}\text { For scores greater than or equal to } 6 \text {, a best practice advisory alert was generated that would suggest the placement of a } \\
\text { social work referral to patients. }\end{array}$ \\
\hline 5 & Patients were offered a social work referral and follow-up. \\
\hline \multicolumn{2}{|c|}{ INTERVENTION MODALITY } \\
\hline 6 & The mode of delivery of the intervention is in-person visits and documented in each patient's electronic medical record. \\
\hline 7 & Patient data were collected via retroactive chart review of the patient electronic medical record. \\
\hline \multicolumn{2}{|c|}{ INTERVENTION CONTEXT } \\
\hline 7 & The intervention occurred in an outpatient medical oncology clinic \\
\hline 8 & The intervention took place in clinic between August 2017 and March 2018. \\
\hline \multicolumn{2}{|c|}{ INTERVENTION TAILORING AND ADAPTING } \\
\hline 9 & This intervention was not intended to be adapted during the study period \\
\hline 10 & This intervention was not intended to be modified during the study period. \\
\hline
\end{tabular}

\section{APPENDIX}




\section{SUPPLEMENTARY MATERIALS}

\section{Figures}

Download: https://journal.binayfoundation.org/article/27349-implementation-of-a-medical-oncology-fellow-initiatedfinancial-toxicity-screening-program-in-outpatient-medical-oncology-clinics/attachment/69951.pdf 